\title{
SHORELINE SAND WAVES AND BEACH NOURISHMENTS
}

\author{
N. van den Berg ${ }^{1}$, A. Falqués ${ }^{1}$ and F. Ribas ${ }^{1}$
}

\begin{abstract}
The effects of the feedback between the changing coastal morphology and the wavefield on the generation and propagation of large scale $(\mathrm{O}(1-10 \mathrm{~km}))$ shoreline sand waves is examined with a quasi-2D morphodynamic model. Traditional shoreline change models do not include this feedback and are only able to describe diffusion of shoreline sand waves and furthermore they are unable to describe migration. It is found with the present model that if there is a dominant littoral drift, the feedback causes downdrift migration of coastline features no matter if they grow or decay. Consistently with previous studies, simulations show that a rectilinear coastline becomes unstable and sand waves tend to grow spontaneously from random perturbations, if the wave incidence angle is larger then about $42^{\circ}\left(\theta_{c}\right)$ at the depth of closure (high angle wave instability). The initial wavelengths at which the sand waves develop are 2-3 km and this is similar to previous linear stability analysis. The implications of high angle wave instability for beach nourishments are investigated. The nourished shoreline retreats initially due to cross-shore transport because the nourished profile is steeper than the equilibrium profile. When a dominant littoral drift is present, the nourishment also migrates downdrift. If the wave angle at the depth of closure is below $\theta_{\mathrm{c}}$ the alongshore transport contributes to the diffusion of the nourishment. However, if the angle is above $\theta_{\mathrm{c}}$ (constant high angle wave conditions) the diffusion is reversed and the nourishment can trigger the formation of a shoreline sand wave train. Numerical experiments changing the proportion of 'high angle waves' and 'low angle waves' in the wave climate show that relatively small proportions of low angle waves slow down the growth of sand waves. These simulations with more realistic wave climates show shoreline sand waves that migrate downdrift maintaining more or less the same amplitude for years.
\end{abstract}

\section{INTRODUCTION}

Large scale shoreline undulations have been observed on various sandy coasts around the world (Bruun 1954, Davidson Arnott and van Heyningen 2003, Ruessink and Jeuken 2002, Thevenot and Kraus 1995, Verhagen 1989) and are commonly called shoreline sand waves. They have a typical alongshore scale in the order of several kilometres and an amplitude in the order of several tens of meters. In general they migrate downdrift at a speed in the order of tens to hundreds $\mathrm{m} / \mathrm{yr}$, maintaining more or less their shape and volume. The variability of the shoreline due to these migrating sand waves can be greater than the long-term coastal trend and should therefore be taken into account in nourishment planning (Stive et. al. 2002). Alongshore variations in the shoreline position imply erosional stretches and the resulting decreased beach width increases dune vulnerability (Ruessink and Jeuken 2002). Furthermore it remains unclear if human intervention in the coastal system could lead to unforeseen interactions with the shoreline sand wave dynamics.

The occurrence of shoreline sand waves have been related to intermittent sediment input: discharge of river sediments (Inman 1987), sediments discharged from inlets (Thevenot and Kraus 1995), artificial injection of a large quantity of sand (Grove et. al. 1987) and welding of shoals or oblique bars on to the shore (Davidson-Arnott and van Heyningen 2003). However, their dynamics is poorly understood. Traditional shoreline models are based on the assumption that large scale shoreline dynamics are driven by gradients in alongshore transport and that detailed surfzone dynamics can be neglected. These models always predict diffusion of shoreline undulations and downdrift migration is only described by including an empirical advection term (Dean 2002, Larson and Kraus 1991, Thevenot and Kraus 1995).

Using a new shoreline model, Ashton et. al. (2001) showed that a sandy coastline can be unstable when it is dominated by high angle wave incidence (incidence angles above $42^{\circ}$ ). Under these conditions small perturbations on an otherwise rectilinear coastline can grow and form large scale rhythmic patterns like shoreline sand waves (see also Ashton et al. 2006a,b). This instability mechanism is referred to as high angle wave instability (HAWI). HAWI was studied further by Falqués and Calvete (2005), who used a linear stability analysis to show the initial formation of shoreline sand waves with typical length scales in the order of 1-10 km and a growth time in the order of years. Crucial for the development of the shoreline instability is the feedback of the shoreline changes and the related bathymetrical changes into the wave transformation. This feedback into the wave transformation leads to gradients in alongshore transport that allow for growth and migration of the shoreline perturbation instead of merely diffusion.

Recent studies by Falqués et. al. (2008) and van den Berg et. al. (2010) used a non-linear

\footnotetext{
1 Applied Physics Department, Universitat Politècnica de Catalunya (UPC), Campus Nord UPC B5, Barcelona, Catalonia, 08034, Spain
} 
morphodynamic model that overcomes some of the limitations of the previous HAWI studies. They confirmed the formation of shoreline sand waves with similar spatial and temporal scales but also showed that very specific conditions are needed for the spontaneous growth of shoreline sand waves. Importantly, the wave incidence angle has to be greater than the critical angle at the depth of closure, it is not sufficient to have high wave incidence angles in deep water. Similarly, the bathymetric perturbation triggering the instability must reach the offshore location where the wave incidence angle is above the critical angle (see also List and Ashton 2006). However, it can be expected that if there is a significant contribution of high angle wave incidence to the wave climate, the HAWI mechanism together with an (periodic) input of a large body of sand could explain the occurrence and dynamics of large scale shoreline sand waves. The unstable conditions could balance the diffusive low angle wave conditions.

The objective of the present study is twofold. The first one is to improve the understanding of the dynamics of shoreline sand waves and the second one is to test the hypothesis that beach nourishments themselves might trigger the growth of shoreline sand waves. We use the non-linear quasi 2D morfodynamic model that was previously used by Falqués et. al. (2008) and van den Berg et. al. (2010). Two cases are studied: 1) rectilinear beach with random perturbations and rectilinear beach with a schematized beach nourishment.

\section{MODEL DESCRIPTION}

The Q2D-morfo model is briefly presented here and a more detailed description can be found in van den Berg et al. (2010). An earlier version was introduced in Falqués et al. (2008), the main difference with the present one being the shoreline updating algorithm at the corresponding boundary condition. This model is a non-linear morphodynamic model developed to simulate large-scale shoreline dynamics. It considers sediment transport in two horizontal dimensions and computes the wave field over the whole domain. Convergence and divergence of sediment transport lead to bathymetric changes which feedback to the wave field in the next time step. A Cartesian frame with horizontal coordinates $x, y$ and vertical coordinate $z$ is used, where $y$ is along the initial mean shoreline orientation. The unknowns are the moving shoreline $x=x_{\mathrm{s}}(y, t)$ and the changing bed level $z=z_{b}(x, y, t)$. The dynamic equation for the bed level is the sediment mass conservation,

$$
\frac{\partial z_{b}}{\partial t}+\frac{\partial q_{x}}{\partial x}+\frac{\partial q_{y}}{\partial y}=0
$$

where $\vec{q}=\left(q_{x}, q_{y}\right)$ is the depth integrated sediment flux with the bed porosity factor included. This equation is discretized by using an explicit second order Adam-Bashfort scheme in time and a finite difference method in space.

\section{Sediment transport}

The sediment transport is computed directly from the wave field via parameterisations. This simplification is common for one-line and N-line models and it allows simulations for large spatial and temporal scales. Small scale surf zone dynamics can however not be reproduced. The total sediment flux is the sum of three terms,

$$
\vec{q}=\vec{q}_{L}+\vec{q}_{C}+\vec{q}_{D}
$$

The first term in equation represents the wave driven alongshore transport. First, the cross-shore integrated sediment transport rate is computed with an extended version of the CERC formula (Komar, 1998):

$$
Q=\mu H_{b}^{5 / 2}\left(\sin \left(2 \alpha_{b}\right)-\frac{2 \mathrm{r}}{\beta} \cos \left(\alpha_{b}\right) \frac{\partial H_{b}}{\partial y}\right)
$$

where $H_{b}(y)$ is the root mean square wave height at breaking, $\alpha_{b}=\theta_{b}(y)-\phi(y)$ is the angle between the wave fronts at breaking and the coastline and $\beta$ is the local swash slope. The constant $\mu$ is proportional to the empirical parameter $\mathrm{K}_{1}$ of the original CERC formula. This model parameter controls the magnitude of the transport and the default value of $\mu=0.2 \mathrm{~m}^{0.5} \mathrm{~s}^{-1}$ corresponds to $\mathrm{K}_{1}=0.7$. The constant $\mathrm{r}=\mathrm{K}_{2} / \mathrm{K}_{1}$, where $\mathrm{K}_{2}$ is the empirical parameter of the second term (Ozasa and Brampton, 1980). The default value used is $r=1$. Then, the sediment flux is computed as 


$$
\vec{q}_{L}=f(x) Q(y)(\sin (\phi(y)), \cos (\phi(y)))
$$

where $f(x)$ is a cross-shore distribution function, qualitatively based on the cross-shore profile of the longshore current (Komar, 1998). The orientation of the coastline $\phi(y)$ is the mean orientation of the bathymetric lines within the surf zone with respect to the y-axis rather than the angle of the shoreline relative to the y-axis. The angle $\phi(y)$ is determined by computing the average orientation within a rectangle with dimensions equal to the surf zone width. This is the orientation felt by the breaking waves.

The second term in equation (2) is a parameterization of cross-shore sediment transport processes. We assume that, on a relatively long time scale, these processes drive the cross-shore profile to an equilibrium profile $\mathrm{z}_{\mathrm{be}}$, so that

$$
\vec{q}_{C}=-\gamma_{x} \frac{\partial\left(z_{b}-z_{b e}\right)}{\partial x}(1,0)
$$

where $\gamma_{x}$ is a cross-shore diffusivity coefficient. The third term in equation (2) is an alongshore diffusivity (in the direction of the surfzone contour lines) that suppresses the growth of small scale noise,

$$
\vec{q}_{D}=-\gamma_{y}\left(\frac{\partial z_{b}}{\partial x} \sin \phi+\frac{\partial z_{b}}{\partial y} \cos \phi\right)(\sin \phi, \cos \phi)
$$

The physical basis for the coefficients $\gamma_{\mathrm{x}}$ and $\gamma_{\mathrm{y}}$ is the diffusivity caused by wave breaking. Thereby, they depend on the wave energy dissipation and their order of magnitude has been estimated by using the expression for momentum mixing due to wave breaking,

$$
v_{t}=M\left(D_{i s s} / \rho\right)^{1 / 3} H
$$

where $M$ is a nondimensional constant, $D_{i s s}$ is the wave energy dissipation per time and area unit, $\rho$ is the water density and $H$ is the root mean square wave height. The order of magnitude of $D_{i s s}$ is estimated as the total energy flux entering the surf zone divided by the area,

$$
D_{i s s} \approx \frac{1}{8} \rho g H_{b}^{2} \frac{c_{g b}}{X_{b}}
$$

where $g$ is the gravity acceleration, $X_{b}$ is the surfzone width and $c_{g b}$ is the group celerity at breaking, computed with the shallow water assumption. We then assume that $\gamma_{x}$ and $\gamma_{y}$ scale with $v_{t}$ so that:

$\gamma_{x}=\varepsilon_{x} v_{t} \psi(x) \quad, \quad \gamma_{y}=\varepsilon_{y} v_{t} \psi(x)$

where $\varepsilon_{\mathrm{x}}, \varepsilon_{\mathrm{y}}$ are nondimensional constants. The shape function $\psi(\mathrm{x})$ has a cross-shore distribution with a maximum of order 1 in the surf zone and decays to almost zero at the depth of closure, $D_{c}$. It depends on the wave height and the position of the shoreline. High waves and an offshore moving shoreline shift $D_{c}$ seaward.

\section{Wave module}

The wave height $H_{b}$ and angle $\theta_{b}$ at breaking are needed for the computation of the sediment transport. The wave module computes the wave field from the wave height, period and angle given at the offshore boundary, based on the wave number irrotationality, the wave energy conservation and the dispersion relation (regular monochromatic waves are assumed)

$$
\frac{\partial k_{x}}{\partial y}-\frac{\partial k_{y}}{\partial x}=0 \quad, \quad \frac{\partial}{\partial x}\left(c_{g} H^{2} \frac{k_{x}}{k}\right)+\frac{\partial}{\partial y}\left(c_{g} H^{2} \frac{k_{y}}{k}\right)=0 \quad, \quad \omega^{2}=g k \tanh (k D)
$$

where $\omega=2 \pi / T_{\mathrm{p}}$ is the radian frequency, $T_{\mathrm{p}}$ is the peak period, $\vec{k}=\left(k_{x}, k_{y}\right)=k(-\cos \theta, \sin \theta)$ is the wave number vector, $D$ is the water depth, $\mathrm{c}_{\mathrm{g}}$ is the group celerity and $\theta$ is the wave crest angle with respect to the $x$-axis. Dissipation by bottom shear stresses is neglected and dissipation by breaking is not included because the wave field is only needed up to breaking. The point of breaking is defined as 
$H=\gamma_{\mathrm{b}} D$ and $\gamma_{\mathrm{b}}$ is the breaking index (the ratio wave height to water depth at breaking).

\section{Boundary conditions}

At the shoreline the following condition is used,

$$
\vec{q}\left(x=x_{s}\right)=\gamma_{s}\left(\frac{\partial z_{b}}{\partial x} \cos \phi_{s}-\frac{\partial z_{b}}{\partial y} \sin \phi_{s}-\beta_{s}\right)\left(\cos \phi_{s},-\sin \phi_{s}\right)
$$

where $\phi_{\mathrm{s}}$ is the angle between the shoreline and the $y$-axis, $\beta_{\mathrm{s}}$ is an equilibrium slope and $\gamma_{\mathrm{s}}$ is the swash zone diffusivity coefficient. This equation simulates the relaxing of the swash slope to the equilibrium slope, $\beta_{\mathrm{s}}$. The coefficient $\gamma_{\mathrm{s}}$ is related to the swash zone relaxation time $\mathrm{T}_{\mathrm{s}}$ by $\gamma_{\mathrm{s}} \sim(\Delta \mathrm{x})^{2} / \mathrm{T}_{\mathrm{s}}$, where $\Delta \mathrm{x}$ is the grid size and $T_{s}$ is of the order of a few hours. At the seaward boundary the sediment flux consists of a residual diffusive cross-shore transport calculated by assuming that the profile relaxes to the equilibrium profile within a certain decay distance from the boundary. At the lateral boundaries there is no diffusive transport and only wave driven alongshore transport is considered.

\section{RESULTS}

\section{Modeling domain and default parameters}

The modelled domain is a $20 \mathrm{~km}$ long stretch of beach with a cross-shore width of $1.2 \mathrm{~km}$. The dry beach is 400 meters wide and a Dean shaped profile is used as the equilibrium cross-shore profile with a prescribed swash slope at the shoreline $(\beta=0.03)$ and the water depth at the offshore boundary, $D_{o}$, is $11 \mathrm{~m}$. A grid with a cell size of $50 \mathrm{~m}$ in alongshore direction and $5 \mathrm{~m}$ in cross-shore direction is used. Model parameter $\mu$, controlling sediment transport rate, is set to a default value of $0.2 \mathrm{~m}^{1 / 2} / \mathrm{s}^{-1}$. The cross-shore diffusivity coefficient, $\varepsilon_{\mathrm{x}}$, is set to 0.05 , based on a realistic cross-shore response time. $\varepsilon_{\mathrm{y}}$ is also set to 0.05 and $\gamma_{\mathrm{s}}$ is set to $0.001 \mathrm{~m}^{2} / \mathrm{s}$. A cross-shore distribution profile is chosen so that the depth of closure, $D_{c}$, is about $7 \mathrm{~m}$ for default wave conditions. The breaking index $\gamma_{b}$ is set to an intermediate value of 0.5 . A time-step of 1.44 minutes is used to satisfy the Courant numerical stability condition and the wave field is computed every 24 hours. As a first approximation, constant wave
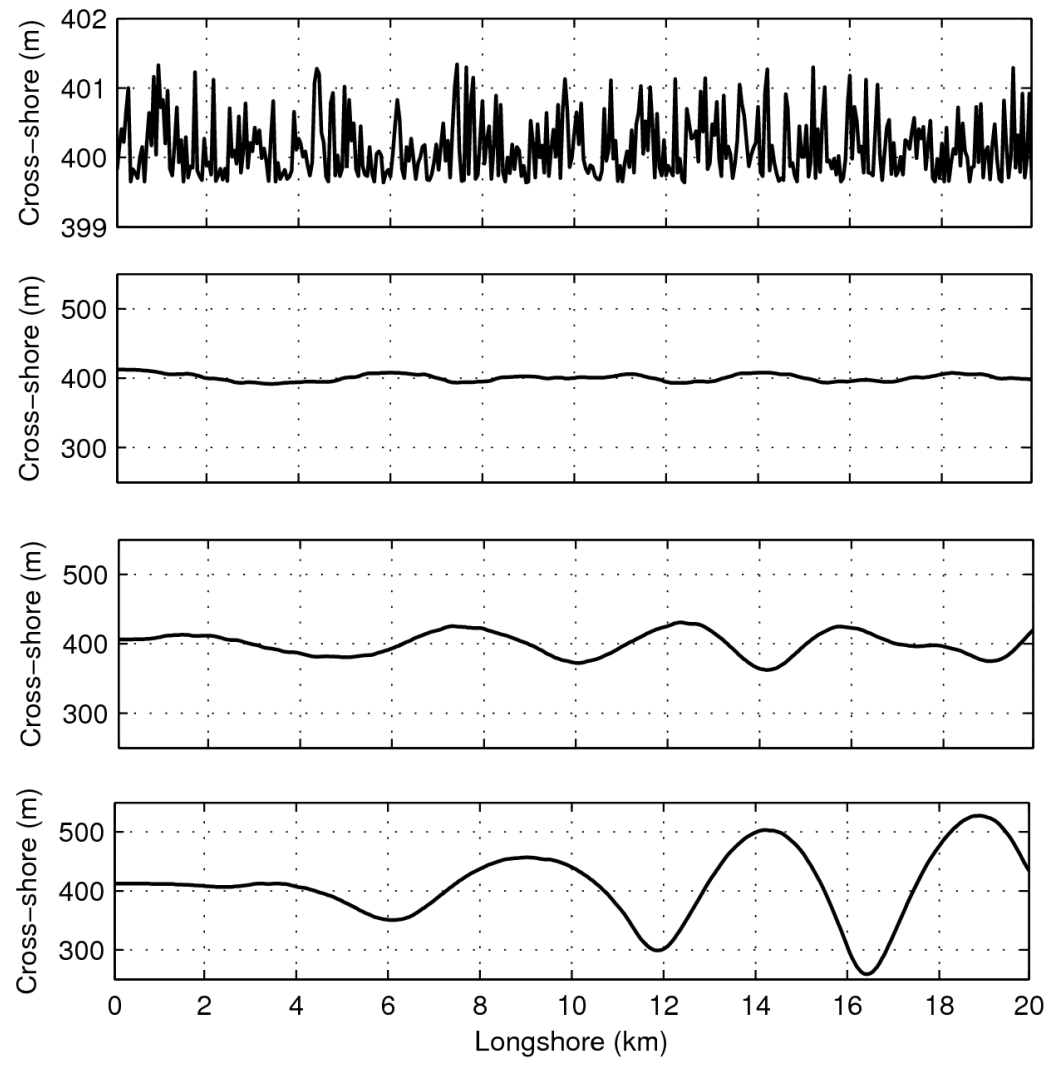

Figure 1, Shoreline evolution for a rectilinear coast with random bathymetric perturbations and $\theta_{0}=60^{\circ}$. Top panel $t=0$, second panel $t=5$ years, third panel $t=10$ years and bottom panel $t=15$ years. 
conditions are given at the offshore boundary, representing an annual average: $\mathrm{H}_{\mathrm{s}}=1.4 \mathrm{~m}, \mathrm{~T}_{\mathrm{p}}=6 \mathrm{~s}$. The wave incidence angle, $\theta_{0}$, is varied for the different simulations but is constant during each simulation except for the last section of the results where we look at the effect of different ratios between high and low wave incidence.

\section{Random perturbations on a rectilinear coastline}

In these simulations small random perturbations of $10 \mathrm{~cm}$ were imposed on the initial bathymetry. These perturbations led to small variations in the wavefield which resulted into small gradients in alongshore transport and subsequently into small fluctuations of the shoreline. For offshore wave incidence angles below about $50^{\circ}$ the bathymetric perturbations were diffused and the small fluctuations in the shoreline remained but they do not increase and the shoreline remained rectilinear. These fluctuations have no real physical meaning as the model is not capable of resolving small scale surfzone morphodynamics. However, they trigger larger scale random perturbations at the length scale where the model makes sense. For an offshore wave angle of $60^{\circ}$ we can see a different evolution (lower 3 panels in figure 1). Wavelengths of about $3 \mathrm{~km}$ emerge from the random fluctuations due to the positive feedback between the morphological changes and the wavefield. Apparently this is the minimal length scale at which HAWI can develop and this is consistent with the findings of Falqués and Calvete (2005). These still very low amplitude undulations started grow and self-organise themselves. After about 5 years a clear sand wave train developed with wavelengths of about 3-4 km and amplitudes of about $10 \mathrm{~m}$. The individual sand waves migrated downdrift at about $400 \mathrm{~m} / \mathrm{yr}$. The amplitude increased faster than the wavelength and after 15 years three sand waves remained in the domain with wavelengths of about $5 \mathrm{~km}$ and amplitudes of about $100 \mathrm{~m}$ (bottom panel in figure 1).

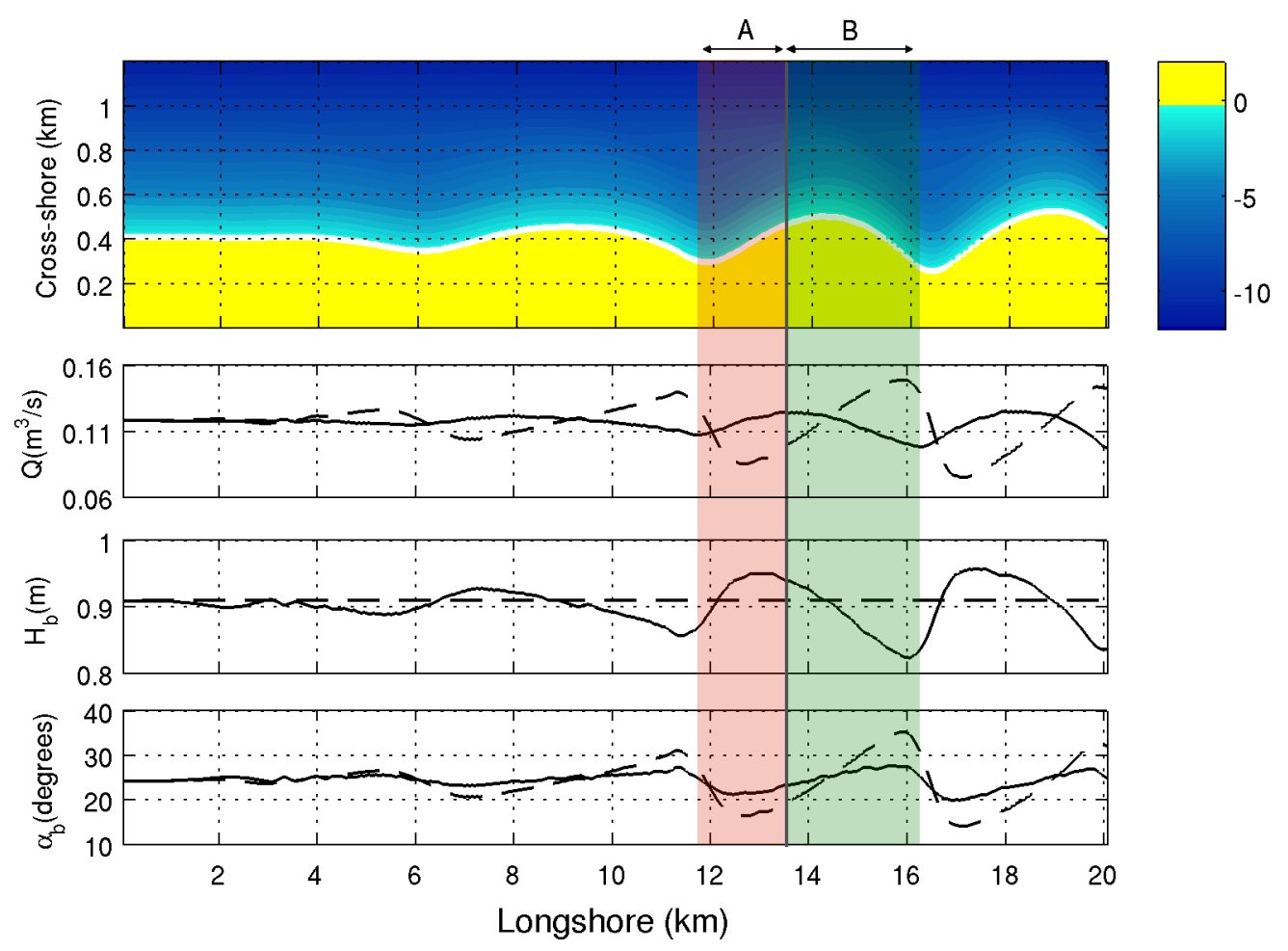

Figure 2, Bathymetry after 15 years for a simulation with random perturbations and $\theta_{0}=60^{\circ}$ (top panel). In the panels below: the plots of the alongshore sediment transport rate, wave height at breaking and relative wave angle at breaking (continuous lines). The red overlay (A) marks the zone of erosion and the green overlay (B) the zone of deposition. The dashed lines represent a snapshot of the corresponding quantities for the traditional shoreline model approach where gradients in $H_{b}$ and $\theta_{b}$ are disregarded.

Figure 2 shows the bathymetry after 15 years and also the related alongshore distribution of the wave driven sediment transport (continuous line in second panel from above). This illustrates the HAWI mechanism. The position of maximum transport at the second sand wave is located updrift of the crest (vertical line). In zone A there is a increasing transport (positive gradient) which leads to erosion. 
Downdrift of the maximum, the transport decreases leading to deposition up to the minimum in transport (zone B). The erosion of the updrift slope and deposition at the crest and downdrift slope leads to growth and downdrift migration. The lower two panels show the alongshore distribution of $\mathrm{H}_{\mathrm{b}}$ and the relative wave angle, $\alpha_{b}$. The sediment transport, $Q$, is a function of these two variables (equation 3 ) and it can be seen that the position of the maximum $\mathrm{Q}$ is dominated by $\mathrm{H}_{\mathrm{b}}$. The dashed lines in figure 2 simulate the traditional shoreline model approach where the wavefield is computed over rectilinear bathymetric lines and the shoreline changes do not feedback into the wavefield. The relative wave angle only depends on changes in the shoreline orientation as the wave angle at breaking is constant just as the wave height at breaking. The alongshore transport is dominated by the gradients in $\alpha_{\mathrm{b}}$ and the absolute transport rates are higher. In this situation, the pattern of erosion and deposition is completely different: erosion over the whole crest and deposition in the troughs. From this figure we can conclude that the direct effect of refraction on the wave angle at breaking leads to relatively lower diffusion rates and that including the indirect effect (wave energy spreading and focussing) leads to gradients in wave height that dominate the transport gradient under high angle wave conditions and allows for growth and migration of shoreline undulations.

Using the same sand wave bathymetry of the previous simulation we will now look what transport gradients would occur under low angle wave conditions $\left(\theta_{0}=30^{\circ}\right)$. In figure 3 the same approach is used as in figure 2 and it shows that under low angle wave conditions refraction is less strong leading to lower gradients in wave angle at breaking. The gradients in wave height at breaking are very small however the absolute value is higher, leading to higher absolute transport rates. The gradients in Q are however controlled by the gradients in $\alpha_{b}$. The resulting transport pattern is similar to the traditional shoreline model approach in figure 2; erosion along the whole crest (zone A) and deposition in the troughs (zone B). This leads to diffusion of the undulations and a stable coastline. Under these low angle wave conditions the differences between the traditional shoreline model (dashed lines) and the present model are small. The reduction of relative wave angle at breaking due to refraction only leads to a small decrease in diffusion rate (the gradients in $\mathrm{Q}$ are smaller).

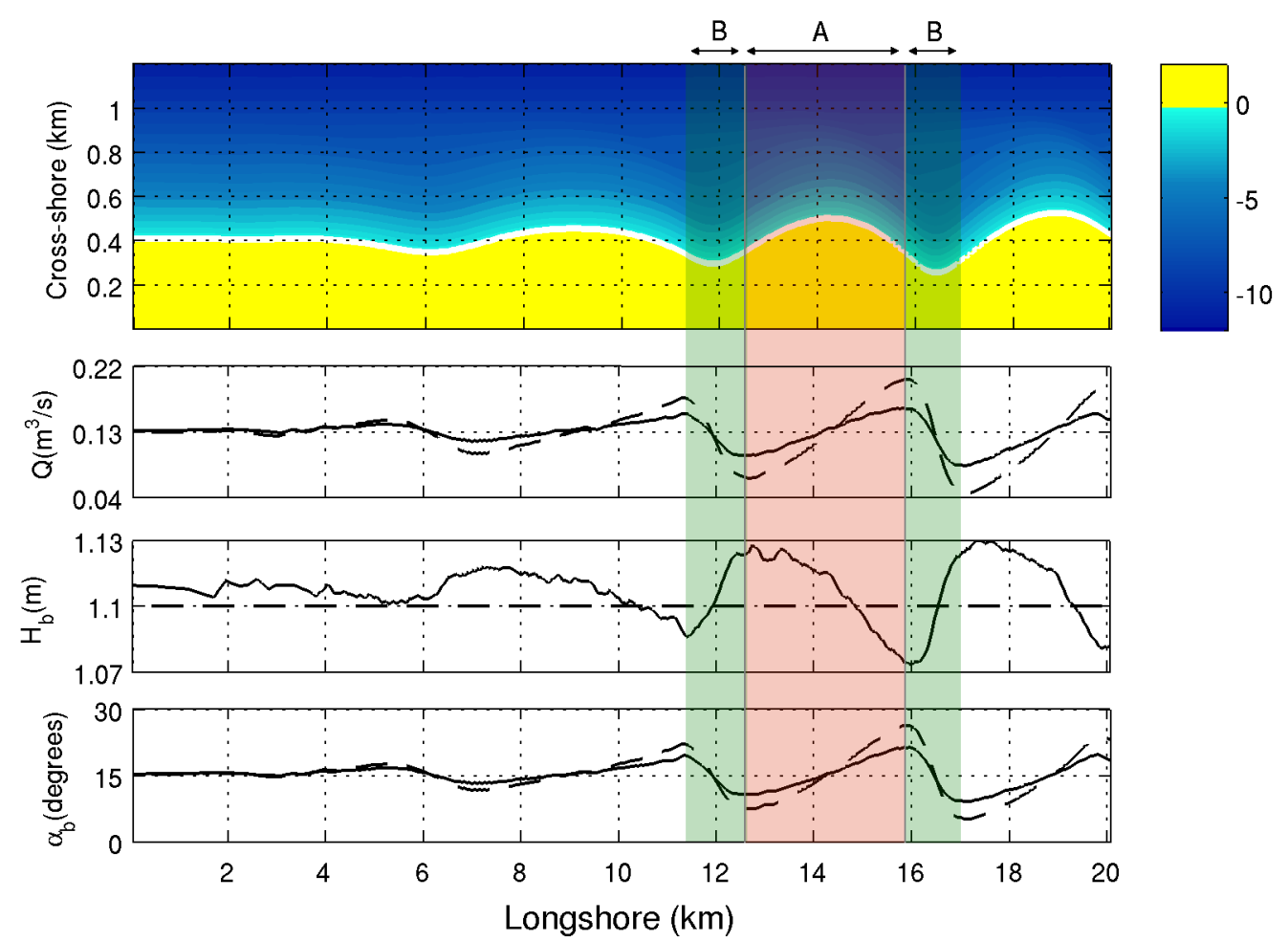

Figure 3, A snapshot of the alongshore sediment transport, wave height at breaking and relative wave angle at breaking (continuous lines) for $\boldsymbol{\theta}_{0}=30^{\circ}$. The quantities have been computed over the bathymetry with shoreline sand waves that developed in a simulation with $\theta_{0}=60^{\circ}$ (top panel). The red overlay (A) marks the zone of erosion and the green overlay (B) the zones of deposition. The dashed lines represent a snapshot of the corresponding quantities for the traditional shoreline model approach where gradients in $H_{b}$ and $\theta_{b}$ are disregarded. 


\section{Schematized beach nourishment}

As an initial approach we will just look at a simple nourishment scheme. The nourishment has a volume of about $0.7 \mathrm{Mm}^{3}$, is $2 \mathrm{~km}$ long and advances the shoreline $100 \mathrm{~m}$. The foot of the beach nourishment is located at $4 \mathrm{~m}$ depth and the cross-shore slope of the perturbation is steeper than the equilibrium slope.

For the simulation with low angle wave incidence the nourishment is placed $6 \mathrm{~km}$ from the updrift boundary. A constant wave incidence angle of $30^{\circ}$ is used and the resulting shoreline evolution can be seen in figure 4 . During the first year the sand of the nourishment got spread out in cross-shore and alongshore direction and the shoreline retreated about 80 meters. This strong initial retreat was mainly due to the cross-shore transport which adjusted the relatively steep nourished profile to the equilibrium profile. Afterwards the diffusion was mainly due to alongshore transport and the diffusion of the nourishment slowed down as it is proportional to its amplitude. After 8 years the shoreline retreated another 10 meters and the crest of the shoreline undulation moved downdrift slightly with about $450 \mathrm{~m}$, which implies a migration rate of $56 \mathrm{~m} / \mathrm{yr}$. A more clear indication for downdrift migration is that the volume of the undulation is greater downdrift of the initial centre of the nourishment. This implies that including the feedback of the shoreline changes into the wavefield can describe downdrift migration even under low angle wave conditions.

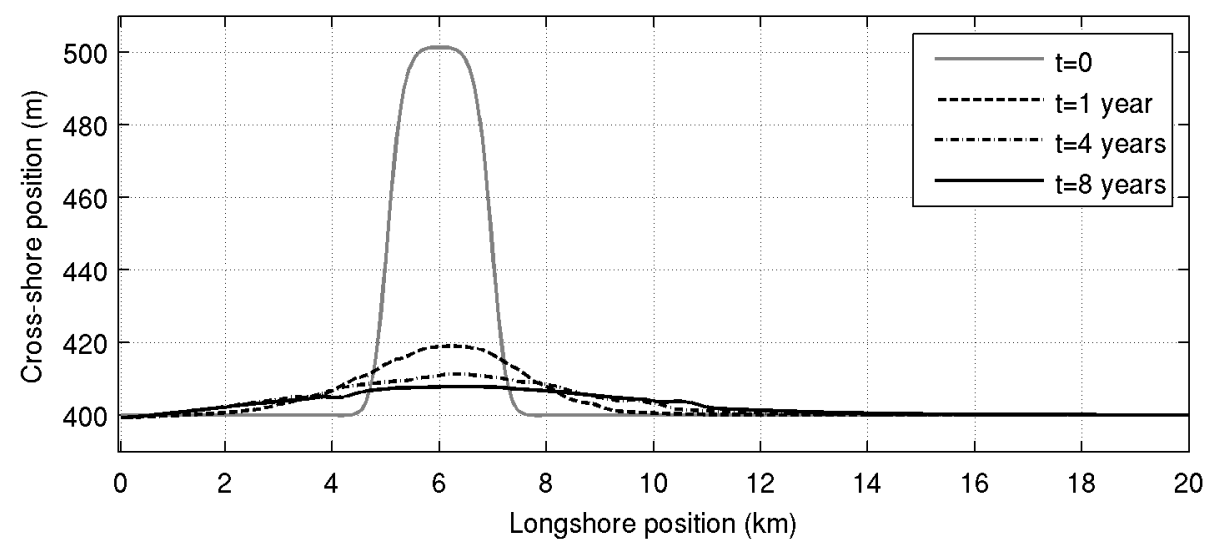

Figure 4, Shoreline evolution of a rectilinear coastline with a beach nourishment at the $6 \mathrm{~km}$ position for $\theta_{0}=30^{\circ}$.

For the simulation with high angle wave conditions $\left(\theta_{0}=60^{\circ}\right)$ the nourishment is placed $3 \mathrm{~km}$ downdrift of the updrift boundary (figure 5). Just as for the low angle conditions, the nourishment initially diffused in cross-shore and alongshore direction and the shoreline retreated about $55 \mathrm{~m}$ during the first half a year. During this diffusional phase the undulation migrated downdrift at a rate of 800 $\mathrm{m} / \mathrm{yr}$. Downdrift of the crest, an erosional zone (trough) developed simply due to gradients in alongshore transport. The transport decreased at the downdrift slope leading to deposition. Further downdrift the transport increased to normal values for a rectilinear coastline which caused a positive gradient and erosion. Due to the transport in cross-shore direction the undulation got spread offshore in the bathymetry until a depth was reached where the wave incidence angle was greater than the critical value of about $42^{\circ}$. This triggered the positive feedback between the wavefield and the shoreline changes and initiated HAWI. Due to HAWI, the crest of the undulation and the downdrift trough started to grow in amplitude.

Even though there was only one initial perturbation multiple shoreline sand waves developed. This is again simply the result of gradients in alongshore transport. Downdrift of the erosional zone the alongshore transport decreased leading to deposition. This new bump continued to grow slowly until the bathymetric changes also triggered HAWI and the bump developed into a second sand wave. The new sand waves developed with a minimal length scale of $2 \mathrm{~km}$. The evolution of the first sand wave was influenced by the nourishment dimensions but the evolution of the downdrift sand waves can be seen as a self-organising process. After 8 years a series of sand waves developed with wavelengths of 3-7 km and amplitudes of $80-250 \mathrm{~m}$ (figure 6). The downdrift migration rate was $350-800 \mathrm{~m} / \mathrm{yr}$, with each relatively smaller downdrift sand wave migrating faster. This simulation shows that when an initial large scale perturbation is present, the development of the shoreline instability and the shoreline sand waves is much faster than for the simulation with random perturbations. 


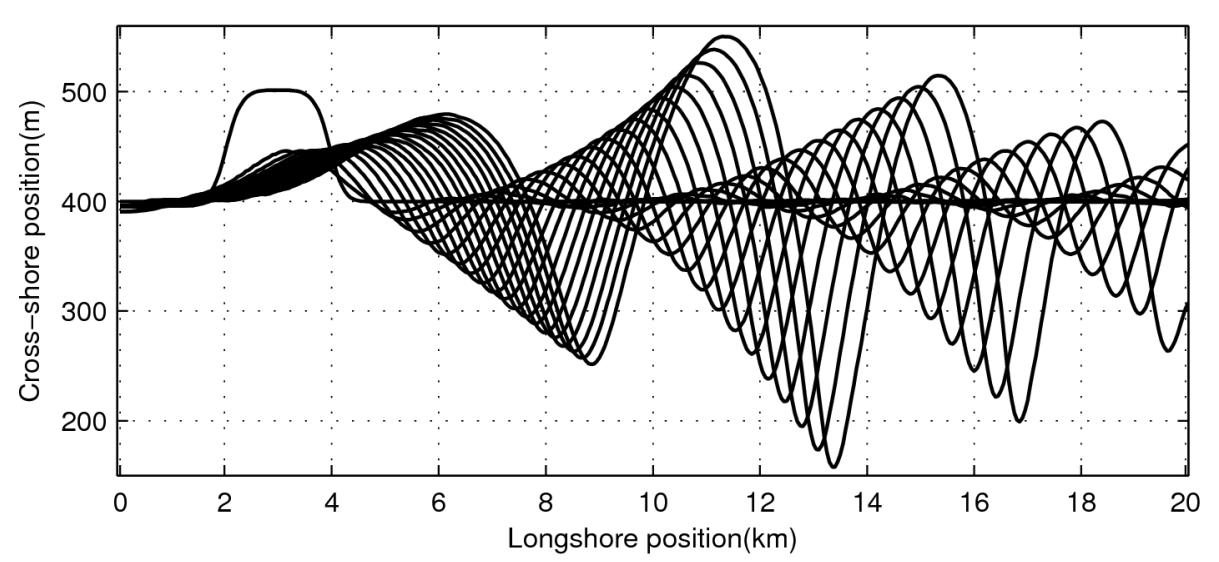

Figure 5, Time evolution of the shoreline for a rectilinear coastline with a beach nourishment at the $3 \mathrm{~km}$ position for $\theta_{0}=60^{\circ}$. The shoreline is plotted every 6 months and the final line corresponds with the result after 8 years.

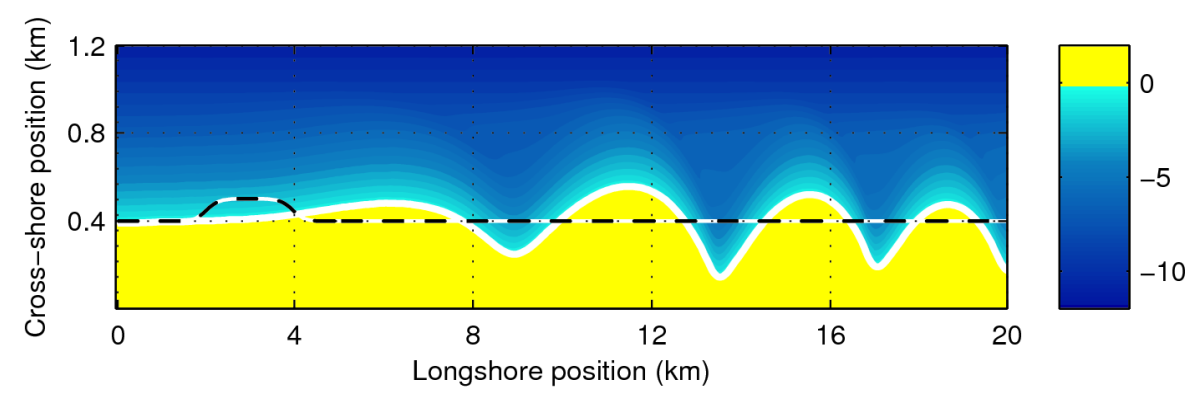

Figure 6, Bathymetry after 8 years for a rectilinear coastline with a beach nourishment at the $3 \mathrm{~km}$ position for $\boldsymbol{\theta}_{0}=\mathbf{6 0 ^ { \circ }}$. The dotted line represents the initial shoreline.

\section{VARYING WAVE INCIDENCE ANGLES}

The development of a sand wave train from a single shoreline perturbation, as described in the previous section, has to the authors knowledge not been observed in nature and this could be explained by the fact that it is very rare to have constant high angle wave incidence. In this section we will look at the development of a beach nourishment under alternating high and low angle wave incidence. It is beyond the scope of this paper to also study the effect of waves coming from the opposite side (in this case negative angles). We use the same initial bathymetry and parameters as in the previous section. The wave incidence angle is alternated every 5 days between $60^{\circ}$ and $30^{\circ}$. The relative contribution of high angle waves or the proportion of unstable conditions is expressed by the parameter U, following the approach by Ashton et. al. (2006a). The evolution of the nourishment for the $U=0$ (stable conditions) and $\mathrm{U}=1$ (unstable conditions) have been discussed in the previous section.

Figure 7 shows the shoreline after 15 years for $U=0.75$ and it can be seen that a shoreline sand wave train developed with a much lower amplitude than for pure high angle wave conditions. During the first 7 years the nourishment diffused until an amplitude of $16 \mathrm{~m}$. The crest of the nourishment migrated downdrift at a rate of $300 \mathrm{~m} / \mathrm{yr}$ and a downdrift erosional zone developed. After these 7 years the diffusion changed into growth and after 15 years the amplitude increased until $27 \mathrm{~m}$ and the wavelength until $9 \mathrm{~km}$. The migration rate over this period was about $120 \mathrm{~m} / \mathrm{yr}$. The downdrift sand wave train already started to develop slowly after half a year. The second sand wave however remained relatively subtle with an amplitude of $15 \mathrm{~m}$ and a wavelength of $5 \mathrm{~km}$. Note that the simulation with $\mathrm{U}=1$ was done over 8 years and the present simulations were done over 15 years.

For $U=0.5$ the unstable conditions are balanced by the stable conditions and the amplitude of the first sand wave, that developed from the nourishment, is again smaller. During the 15 years the nourishment diffused at a decreasing rate. This resulted in a crest with an amplitude of $12 \mathrm{~m}$. An erosional zone with an amplitude of $2 \mathrm{~m}$ developed but a downdrift sand wave train did not develop. 
The crest of the nourishment migrated downdrift at a rate of $130 \mathrm{~m} / \mathrm{yr}$. For $\mathrm{U}=0.25$ no erosional zone developed and the nourishment simply diffused until an amplitude of $7 \mathrm{~m}$ and migrated downdrift. Comparing this shoreline evolution after 8 years with the simulation with $U=0$ shows that the amplitude is similar but that the downdrift migration for $U=0.25$ is twice as fast at $120 \mathrm{~m} / \mathrm{yr}$.

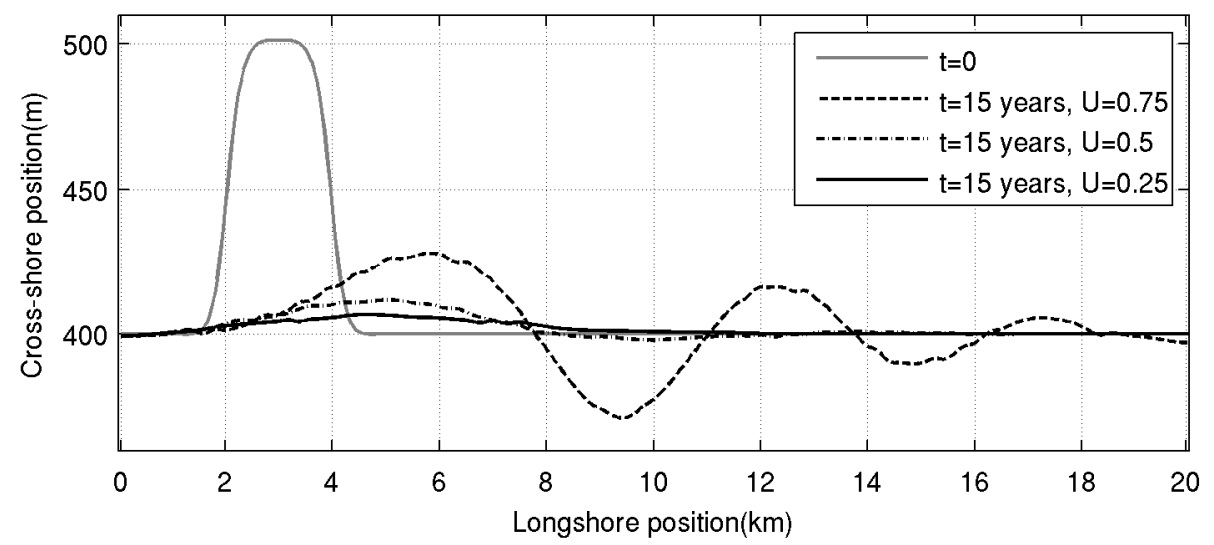

Figure 7, Shoreline plot of the initial rectilinear bathymetry with a beach nourishment at the $3 \mathrm{~km}$ position $(\mathrm{t}=\mathbf{0})$. The three other lines show the shoreline after 15 years for different proportions (U) of $60^{\circ}$ (unstable) and $30^{\circ}$ (stable) offshore wave angles.

\section{CONCLUSIONS}

Simulations with a non-linear quasi 2D morfodynamic model show that for high angle wave incidence conditions an otherwise rectilinear sandy coastline can be unstable leading to the formation of shoreline sand waves from initial random perturbations. The obtained initial spatial scale $(2-3 \mathrm{~km})$ is consistent with the results of linear stability analysis (Falqués et. al., 2005).

The development of sand waves from random perturbations was relatively slow (5-10 years) but when a schematized beach nourishment was used as an initial perturbation, the sand wave train developed faster (1-3 years). As default wave conditions we used constant $H_{s}=1.4 \mathrm{~m}$ and $\mathrm{T}_{\mathrm{p}}=6 \mathrm{~s}$. Under constant high angle wave incidence $\left(\theta_{0}=60^{\circ}\right)$ the single nourishment developed into a downdrift migrating shoreline sand wave and triggered the growth of a downdrift sand wave train through a chain reaction in alongshore sediment gradients. The formation of the sand wave train can be seen as a selforganising process of the shoreline. After 8 years the sand waves developed amplitudes of 80-250 m and wavelengths of 3-7 km and they migrated downdrift at a rate of 350-800 m/yr.

The continuous growth of the sand waves in the simulations with high angle wave conditions do not describe existing observations of shoreline sand wave dynamics, where the sand waves migrate downdrift maintaining more or less their volume. Simulations with a beach nourishment and more realistic wave conditions (using different proportions of high and low angle wave incidence) show promising results. Including a small proportion of low angle waves led to a slower development of the shoreline instability and resulted into sand waves that maintained their volume for years while they migrated downdrift at rates of $120-300 \mathrm{~m} / \mathrm{yr}$.

For an equal proportion of high and low angle waves, the initial nourishment slowly diffused while it migrated downdrift. Even for constant low angle wave conditions the model predicted a downdrift migration of $56 \mathrm{~m} / \mathrm{yr}$. These results support the hypothesis that the feedback between the changing morphology and the wave field is vey important to sand wave dynamics. In particular it is crucial for explaining the migration of already present sand waves, both for high and low angle wave conditions. In addition, this feedback reduces shoreline diffusivity or can even reverse it in case of dominant high angle wave conditions (sand wave growth).

\section{ACKNOWLEDGMENTS}

This research has been funded by the Spanish Ministerio de Educación e Innovación through research grant CTM2009- 11892/ IMNOBE and a FPI scholarship for the first author within the research grant CTM2006-08875/ MAR. 


\section{REFERENCES}

Ashton A., A.B. Murray and O. Arnault, 2001. Formation of coastline features by large-scale instabilities induced by high-angle waves. Nature, 414, 296-300.

Ashton A. and A.B. Murray, 2006a. High-angle wave instability and emergent shoreline shapes: 1. Modeling of sand waves, flying spits, and capes. J.Geophys.Res, 111, F04011, doi:10.1029/2005JF000422.

Ashton A. and A.B. Murray, 2006b. High-angle wave instability and emergent shoreline shapes: 2. Wave climate analysis and comparisons to nature. J.Geophys.Res, 111, F04012, doi:10.1029/2005JF000423.

Bruun, P., 1954. Migrating sand waves or sand humps, with special reference to investigations carried out on the Danish North Sea Coast. Proc. 5th Int. Conf. Coastal Eng. ASCE, New York, 269- 295.

Davidson-Arnott, R.G.D. and A. van Heyningen, 2003. Migration and sedimentology of longshore sandwaves, Long Point, Lake Erie, Canada. Sedimentology 50, 1123-1137.

Dean, R. G., 2002. Beach nourishment. Theory and practice. World Scientific, Singapore

Falqués A. and D. Calvete, 2005. Large scale dynamics of sandy coastlines. Diffusivity and instability. J. Geophys. Res., 110, C03007,doi:10.1029/2004JC002587.

Falqués A., N. van den Berg and D. Calvete, 2008. The role of cross-shore profile dynamics on shoreline instability due to high angle waves. Proc. $32^{\text {nd }}$ Int. Conf. Coastal Eng. World Scientific, Singapore.

Grove, R.S., C.J. Sonu and D.H. Dykstra, 1987. Fate of a massive sediment injection on a smooth shoreline at san onofre, california. In: Coastal Sediments 1987. Am. Soc. of Civ. Eng., pp. 531538.

Inman, D.L., 1987. Accretion and erosion waves on beaches. Shore and Beach 55 (3/4), 61-66.

Komar, P.D., 1998. Beach Processes and Sedimentation, 2nd Edition. Prentice Hall, Englewood Cliffs, N.J.

Larson M. and N.C. Kraus, 1991. Mathematical modeling of the fate of beach fill. Coastal Eng., 16, 83114.

List, J.H. and A.D. Ashton, 2007. A circulation modeling approach for evaluating the conditions for shoreline instabilities. Coastal Sediments 2007. ASCE Conf. Proc. 239, 25.

Ozasa, H. and A.H. Brampton, 1980. Mathematical modelling of beaches backed by seawalls. Coastal Eng. 4, 47-63.

Ruessink, B.G. and M.C.J.L. Jeuken, 2002. Dunefoot dynamics along the dutch coast. Earth Surface Processes and Landforms 27, 1043-1056.

Stive M.J.F., S.G.J. Aarninkhof, L. Hamm, H. Hanson, M. Larson, K.M. Wijnberg, R.J. Nicholls and M. Capobianco, 2002. Variability of shore and shoreline evolution. Coastal Engineering, 47, 211235, DOI: 10.1016/S0378-3839(02)00126-6.

Thevenot M.M and N.C. Kraus, 1995. Longshore sandwaves at Southampton Beach, New York: observations and numerical simulation of their movement. Mar. Geology, 126, 249-269.

van den Berg, N., A. Falqués and F. Ribas, 2010. Long-term evolution of nourished beaches under high angle wave conditions. J. Marine Systems, in press

Verhagen, H.J., 1989. Sand waves along the Dutch coast. Coastal Eng., 13, 129-147. 